\title{
Involvement of the Subscapular Bursa as a Cause of Throwing Pain
}

\author{
Hiroaki Inui*, Katsuya Nobuhara \\ Nobuhara Hospital \& Institute of Biomechanics, Japan
}

Received: June 29, 2015; Accepted: August 22, 2015; Published: September 29, 2015

*Corresponding author: Hiroaki Inui, Nobuhara Hospital \& Institute of Biomechanics, 720 Haze, Issaicho, Tatsunoshi, Hyogo 679-4017, Japan, Tel: 81-0791-66-0981; Fax: 81-0791-66-2687; E-mail: inuhiro123@yahoo.co.jp

\begin{abstract}
Little attention has been paid to a role of the subscapular bursa keeping smooth movement of the shoulder. We hypothesized that irritation in the subscapular bursa causes throwing pain and investigated in which position pain would occur in a clinical scenario and effectiveness of distension arthrography for pain relief in baseball players. One hundred and ten baseball players with shoulder pain were enrolled in this study. All underwent examination of whether pain was provoked with arm rotation at different angles of abduction before and after arthrography. Factors including skill level, playing position, symptom duration, and concurrent injury of the rotator cuff tendon were investigated to affect the results. All patients experienced pain with external rotation at $135^{\circ}$ of abduction before arthrography, and the pain was reduced after arthrography in 92 players $(84 \%)$. Thirty-three patients could continue their playing level 6 months after treatment, while 59 players experienced pain recurrence. Eighteen patients (16\%) could not return to their playing level without treatment efficacy. Symptom duration was the only additional factor that affected the results. Irritation in the subscapular bursa plays a role in the development of disabled throwing shoulders. Distension arthrography is an effective procedure for pain relief.
\end{abstract}

Keywords: Subscapular bursa; Throwing injury; Baseball pitching; Arthrography

\section{Introduction}

Bursae exist in many parts of the body where a considerable degree of motion between parts of the anatomy occurs but where no cartilaginous joint is required [1]. Particularly in areas of the shoulder joint where the muscles or tendons and bones cross each other, bursae between them play important roles in maintenance of joint function [2]. Many previous studies have clarified both anatomically and clinically that the subacromial bursa helps the greater tuberosity of the humerus to smoothly glide under the coracoacromial arch [2-6]. However, only a few studies have investigated the subscapular bursa $[7,8]$ and the clinical importance of this bursa remains incompletely understood $[9,10]$. Colas et al. [8] studied the course of the subscapularis muscle and the anatomy of the subscapular and subcoracoid bursae. Their cadaveric study indicated that the superior distal band of the subscapularis muscle coils along the coracoid process during external rotation in elevation and that the bursae play an important role in the suppression of friction associated with those movements. We hypothesized that friction of the subscapularis tendon coiling along the coracoid process often causes pain during throwing motion and investigated in which position pain would occur in a clinical scenario.

\section{Methods}

This study involved 110 baseball players who visited our hospital for consultation regarding their symptoms and who were followed up for at least 6 months. All were men with an average age of 27 years (range, 16-36 years). The dominant arm was affected in all players. The subjects comprised 52 high schooling, 11 collegiate, 9 professional, and 38 recreational level players. Their baseball playing positions were 50 pitchers, 9 catchers, 19 infielders, and 32 outfielders.

\section{Clinical features}

All players complained of shoulder pain during throwing, especially in the acceleration phase, and stated that their performance level was decreased owing to throwing pain. The passive glenohumeral range of motion was assessed using a large goniometer. Angles of internal and external rotations in the coronal plane at $90^{\circ}$ of abduction were measured in bilateral sides. Measurements were recorded with each subject lying supine to stabilize the scapula. The dominant extremity showed more external rotation at $90^{\circ}$ of abduction and less internal rotation at $90^{\circ}$ of abduction than did the contralateral extremity. The mean external rotation and internal rotation with the dominant extremity were $105^{\circ} \pm 13^{\circ}$ and $50^{\circ} \pm 12^{\circ}$, respectively, and those with the contralateral extremity were $101^{\circ} \pm 14^{\circ}$ and $59^{\circ} \pm 11^{\circ}$, respectively.

\section{Distension arthrography}

Ten milliliters of dye compounded with $10 \mathrm{ml}$ of local anesthetic was injected into the joint. In 29 patients (26\%), leakage or pooling of the dye in the supraspinatus or infraspinatus tendons occurred (Figure 1). After evaluation, the shoulder was forced to internally rotate to distend the dye to the subscapularis bursa. This direction of dye distension was confirmed with plain radiographs after arthrography (Figure 2). In 14 patients, the dye also leaked from the bicipital groove. 


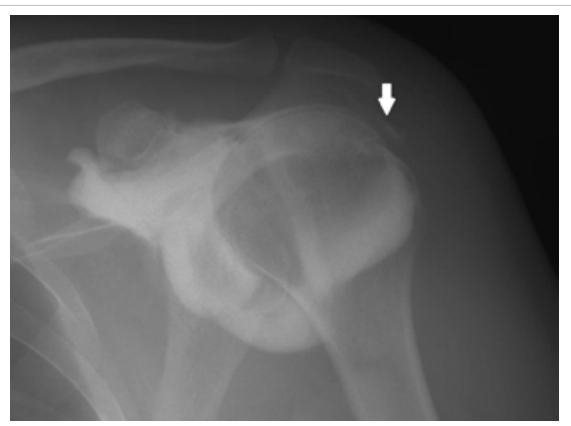

Figure 1: The antero-posterior x-ray image with the arm internally rotated shows the leakage of the dye into the ISP tendon (the white arrow), indicating its tendon injury.
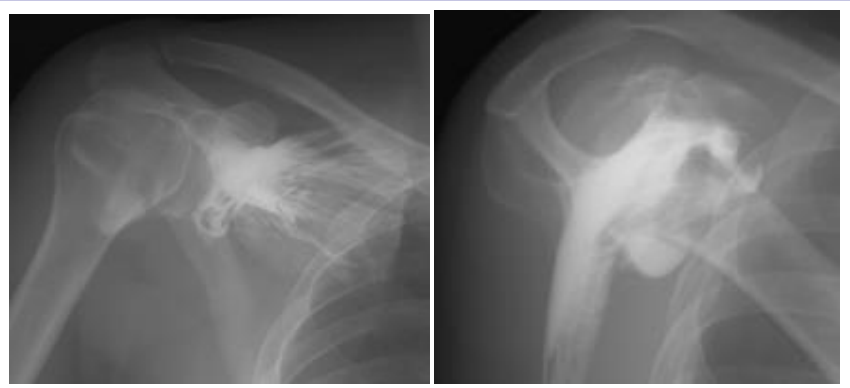

Figure 2: a. The anterior-posterior $x$-ray image shows the dye bursting to the medial side below the coracoid process. $b$. The scapular $Y$ view of the same patient shows the dye bursting anterior to the bone. The images indicated the dye distended to the subscapular bursa.

\section{Evaluation and statistical analysis}

The patients were examined to determine in which position their pain was provoked. The treatment was considered effective when pain was not provoked with arm rotation 1 or 2 weeks after arthrography. The patients were divided into three groups according to whether they could return to their premorbid playing level: Group A could play at their preinjury level 6 months after the treatment; in Group B, the treatment was effective, but pain was either not adequately reduced to return to their premorbid playing level or recurred in 6 months; and in Group C, the treatment was not effective and patients could not return to their playing level. Factors including skill level, playing position, symptom duration, and concomitant injury of the rotator cuff tendon were investigated with respect to their ability to affect the arthrography outcome.

Fisher's exact probability test was used to detect statistical differences between two groups regarding the results, and a statistically significant difference was considered to exist at $p<$ 0.05 . The chi-square test was used for statistical analysis across four subgroups.

\section{Results}

Pain tended to be provoked with greater arm raising and extension (Table 1), and pain was provoked in all patients by external rotation at $135^{\circ}$ of abduction (Figure 3). Pain with external rotation at $135^{\circ}$ degrees of abduction decreased after arthrography in 92 players (84\%). Thirty-three patients could continue at their playing level 6 months after treatment (Group A), while 59 patients either did not have adequate pain relief to return to their premorbid playing level or the pain recurred in 6 months (Group B). Eighteen patients (16\%) were not relieved from pain and could not return to their playing level (Group C).

\section{Skill level}

We divided the subjects into four subgroups according to playing level. These four subgroups comprised 48 high schooling, 9 collegiate, 8 professional, and 27 recreational level players. Group A included 14 high school, 4 collegiate, 2 professional, and 13 recreational players; Group B, 34 high school, 5 collegiate, 6 professional, and 14 recreational players; and Group C, 4 high school, 2 collegiate, 1 professional, and 11 recreational players. Skill level did not affect the arthrography outcome (Table 2).

\section{Baseball playing position}

The patients comprised 46 pitchers, 5 catchers, 14 infielders, and 27 outfielders. Group A included 15 pitchers, 3 catchers, 7 infielders, and 8 outfielders; Group B, 31 pitchers, 2 catchers, 7 infielders, and 19 outfielders; and Group C, 4 pitchers, 4 catchers, 5 infielders, and 5 outfielders. Playing position did not affect the arthrography outcome (Table 3).

\section{Symptom duration}

Fifty-one patients were treated for less than 3 months after symptom onset, and their symptom duration was considered to be short. Fifteen patients with short-duration and 18 patients

Table 1: Percentage of players with provoked rotational pain at different positions.

\begin{tabular}{|c|c|c|}
\hline \multirow{2}{*}{ abduction angle } & \multicolumn{2}{|c|}{ Rotation } \\
\cline { 2 - 3 } & Internal rotation & External rotation \\
\hline $0^{\circ} \mathrm{a}$ & $/$ & 15 \\
$90^{\circ} \mathrm{a}$ & 15 & 50 \\
$90^{\circ \mathrm{b}}$ & 8 & 96 \\
$135^{\circ} \mathrm{a}$ & 9 & 100 \\
\hline
\end{tabular}

${ }^{a}$ rotation in the scapular plane, ${ }^{\mathrm{b}}$ rotation in the coronal plane

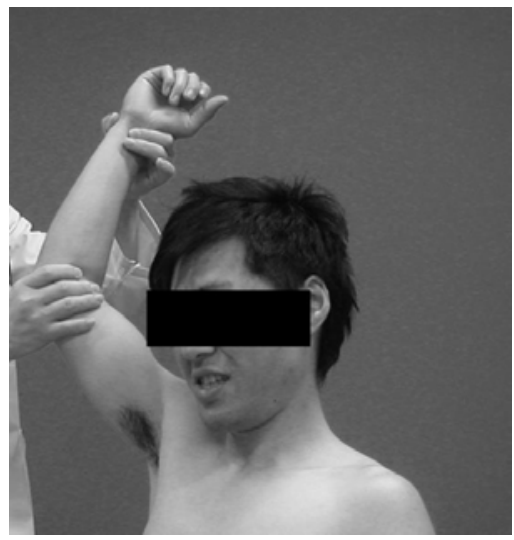

Figure 3: Pain was provoked with the arm externally rotated in 135 degrees of abduction. 
with long-duration symptoms belonged to Group A, 33 with short-duration and 26 with long-duration symptoms belonged to Group B, and 3 with short-duration and 15 with long-duration symptoms belonged to Group C. There were more patients with short-duration symptoms in Groups A and B than in Group C (Fisher's exact probability test, $P=0.009$ ) (Table 4 ).

\section{Concomitant injury in rotator cuff tendon}

Twenty-nine patients demonstrated pooling of dye in the rotator cuff, indicating injury to this structure. Nine patients with cuff tears and 24 without cuff tears belonged to Group A, 16 with cuff tears and 43 without cuff tears belonged to Group $\mathrm{B}$, and 4 with cuff tears and 14 without cuff tears belonged to Group C. Tendon injury did not affect the result. In fact, a higher proportion of rotator cuff injury was noted in patients in Groups $A$ and $B$, in whom the treatment proved effective (Table 5).

\section{Discussion}

Many lesions are reportedly associated with throwing injuries, including articular sided tears of the supraspinatus or infraspinatus muscle, labral lesions, Bennett lesions, humeral head lesions or cysts, and glenoid bony lesions [11-19]. However, most disabled throwing shoulders improve without surgical intervention, and the findings of such lesions are not always related to the patient's symptoms $[15,20,21]$, suggesting other causes of the shoulder disability.

The subscapularis bursa lies between the subscapularis muscle and scapula under the coracoid process. The bursa helps the subscapularis muscle to coil around the coracoid process, especially during external rotation in elevation $[8,22]$.

\section{Table 2 Skill level.}

\section{Group}

Effective (A \& B)

Not effective (C)

\section{Skill level}

high school collegiate professional recreational

\begin{tabular}{|c|l|l|l}
\hline 48 & 9 & 8 & 27 \\
4 & 2 & 1 & 11 \\
\hline
\end{tabular}

Table 3 Baseball playing position.

\begin{tabular}{|c|c|c|c|c|}
\hline \multirow{2}{*}{ Group } & \multicolumn{4}{|c|}{ Playing position } \\
\cline { 2 - 5 } & pitcher & catcher & infielder & outfielder \\
\hline Effective (A \& B) & 46 & 5 & 14 & 27 \\
Not effective (C) & 4 & 4 & 5 & 5 \\
\hline
\end{tabular}

Table 4 Symptom duration.

\begin{tabular}{|c|c|c|}
\hline \multirow{2}{*}{ Group } & \multicolumn{2}{|c|}{ Duration } \\
\cline { 2 - 3 } & less than3 months & 3 months or more \\
\hline Effective (A \& B) & 48 & 44 \\
Not effective (C) & 3 & 15 \\
\hline
\end{tabular}

Table 5 Combined injury.

\begin{tabular}{|c|c|c|}
\hline Group & Cuff tear + & Cuff tear - \\
\hline Effective (A \& B) & 25 & 67 \\
Not effective (C) & 4 & 14 \\
\hline
\end{tabular}

Irritation in this bursa may disturb throwing motion, and the arm is forced to rotate in such situations. In fact, pain tends to be provoked during external rotation with greater arm elevation and horizontal abduction in the clinical setting. The current study also showed that filling the joint and its bursa with liquid dye after arthrography reduced rotational pain in $84 \%$ of the players.

The arm position relative to the trunk during throwing is approximately $90^{\circ}$ to $100^{\circ}$ of abduction [23]. In the present study, there was a discrepancy in comparison of the angle of abduction at which pain was provoked. We surmised that the reason for this discrepancy was that the arm was examined passively. During actual throwing activity, the scapulohumeral relationship approaches that with the arm passively elevated at $135^{\circ}$ of abduction to generate rotational torque.

More patients in Groups A and B had short-duration symptoms ( $<3$ months) than in Group C, indicating that treatment efficacy is affected by symptom duration. If athletes with symptomatic shoulders continue playing baseball without treatment, their condition will worsen to more advanced stages until no treatment is effective. Friction of the subscapularis tendon might cause inflammation in the subscapular bursa. When inflammation is localized, it may resolve spontaneously. However, in more advanced stages, irritation in the bursa becomes extensive, and adhesion may develop, disturbing the gliding motion of the tendon. Restriction in the glenohumeral joint movement might affect coordination of the glenohumeral, scapulothoracic, and trunk movements, decreasing throwing performance or causing other injuries. Thus, we should educate athletes and their coaches to address throwing disability as quickly as possible.

Group B included patients whose symptoms recurred in less than 6 months despite the fact that distension arthrography temporarily relieved their pain. Some shoulder joint characteristics, including subtle instability, might predispose a player to developing symptom recurrence; however, the current study could not elucidate why their throwing pain recurred. Further shoulder examination for subtle instability or throwing motion analysis to investigate abnormal biomechanics is needed. If the cause of throwing pain is known, training for proper throwing motion could prevent recurrence.

To our knowledge, no author has ever pointed out the importance of the subscaplar bursa causing throwing pain. Hopefully, function of the subscapular bursa should be highlighted and more attention should be paid to its anatomy. We think physical therapies can alleviate further inflammation or damage with continued throwing by approaching scapular position or orientation. Myers et al. [24] demonstrated the scapula tipped posteriorly until maximum glenohumeral external rotation during throwing motion. Stretching the pectoralis minor muscle [25] might help this posterior tipping of the scapula and decrease glenohumeral contribution at maximum shoulder external rotation in throwing.

This retrospective study had some limitations. We could not determine in which cases distension arthrography would be effective. Additionally, we could not determine how 
involvement of the subscapular bursa relates to previously reported pathological conditions such as internal impingement $[16,19]$, glenohumeral internal rotation deficit [26], or SICK scapula syndrome [27]. Further prospective studies with larger population are needed.

\section{References}

1. Agur AMR, Lee JM. Grant's atlas of anatomy. 9th ed. Philadelphia: Williams \& Wilkins; 1991.

2. Codman EA. The Shoulder: Rupture of the Supraspinatus Tendon and Other Lesions in Or about the Subacromial Bursa. Florida: Kreiger; 1934.

3. Duranthon LD, Gagey OJ. Anatomy and function of the subdeltoid bursa. Surg Radiol Anat. 2001; 23(1): 23-5.

4. Funk L, Levy O, Even T, Copeland SA. (2006). Subacromial plica as a cause of impingement in the shoulder. J Shoulder Elbow Surg. 2006; 15(6):697-700. doi: 10.1016/j.jse.2006.03.009

5. Hodgson RJ, O'Connor PJ, Hensor EM, Barron D, Robinson P. Contrastenhanced MRI of the subdeltoid, subacromial bursa in painful and painless rotator cuff tears. Br J Radiol. 2012; 85(1019):1482-7. doi: $10.1259 / \mathrm{bjr} / 45423226$

6. Neer CS 2nd. Impingement lesions. Clin Orthop Relat Res. 1983; (173):70-7.

7. Birnbaum K, Prescher A, Heller KD. Anatomic and functional aspects of the kinetics of the shoulder joint capsule and the subacromial bursa. Surg Radiol Anat. 1998; 20(1):41-5.

8. Colas F, Nevoux J, Gagey O. The subscapular and subcoracoid bursae: descriptive and functional anatomy. J Shoulder Elbow Surg. 2004; 13(4), 454-8. doi: 10.1016/s1058274604000473.

9. Andren L, Lundberg BJ. Treatment of Rigid Shoulders by Joint Distension during Arthrography. Acta Orthop Scand. 1965; 36:45-53.

10. Nobuhara K, Supapo AR, Hino T. Effects of joint distention in shoulder diseases. Clin Orthop Relat Res. 1994; (304):25-9.

11. Andrews JR, Broussard TS, Carson WG. Arthroscopy of the shoulder in the management of partial tears of the rotator cuff: a preliminary report. Arthroscopy. 1985; 1(2):117-22.

12. Bennett GE. Elbow and shoulder lesions of baseball players. Am J Surg. 1959; 98:484-92.

13. Connell DA, Potter HG, Wickiewicz TL, Altchek DW, Warren RF. Noncontrast magnetic resonance imaging of superior labral lesions. 102 cases confirmed at arthroscopic surgery. Am J Sports Med. 1991; 27(2):208-13.
14. Halbrecht JL, Tirman P, Atkin D. Internal impingement of the shoulder: comparison of findings between the throwing and nonthrowing shoulders of college baseball players. Arthroscopy. 1999; 15(3):253-8.

15. Heyworth BE, Williams RJ 3rd. (2009). Internal impingement of the shoulder. Am J Sports Med. 2009; 37(5):1024-37. doi: $10.1177 / 0363546508324966$.

16. Jobe CM. Superior glenoid impingement. Current concepts. Clin Orthop Relat Res. 1996; (330):98-107.

17. Kaplan LD, McMahon PJ, Towers J, Irrgang JJ, Rodosky MW. Internal impingement: findings on magnetic resonance imaging and arthroscopic evaluation. Arthroscopy. 2004; 20(7):701-4. doi: 10.1016/j.arthro.2004.06.006

18.Snyder SJ, Karzel RP, Del Pizzo W, Ferkel RD, Friedman MJ. SLAP lesions of the shoulder. Arthroscopy. 1990; 6(4):274-9.

19. Walch G, Liotard JP, Boileau P, Noel E. Postero-superior glenoid impingement. Another impingement of the shoulder. J Radiol. 1993; 74(1):47-50.

20.Connor PM, Banks DM, Tyson AB, Coumas JS, D'Alessandro DF. Magnetic resonance imaging of the asymptomatic shoulder of overhead athletes: a 5-year follow-up study. Am J Sports Med. 2003; 31(5): 724-7.

21. Miniaci A, Mascia AT, Salonen DC, Becker EJ. Magnetic resonance imaging of the shoulder in asymptomatic professional baseball pitchers. Am J Sports Med. 2002; 30(1):66-73.

22. Dugas JR CD, O`brien SJ. Gross and microscopic anatomy of the shoulder. The unstable shoulder. 1999; 77-50.

23. Andrews JR BL. Instability mechanism in the throwing athlete. 1999; 77-89.

24. Myers JB, Laudner KG, Pasquale MR, Bradley JP, Lephart SM. Scapular position and orientation in throwing athletes. Am J Sports Med. 2005; 33(2):263-71.

25. Borstad JD, Ludewig PM. Comparison of three stretches for the pectoralis minor muscle. J Shoulder Elbow Surg, 15(3): 324-30. doi: 10.1016/j.jse.2005.08.011

26. Burkhart SS, Morgan CD, Kibler WB. The disabled throwing shoulder: spectrum of pathology Part III: The SICK scapula, scapular dyskinesis, the kinetic chain, and rehabilitation. Arthroscopy. 2003; 19(6):64161.

27. Burkhart SS, Morgan CD, Kibler WB. The disabled throwing shoulder: spectrum of pathology Part I: pathoanatomy and biomechanics. Arthroscopy. 2003; 19(4):404-20. doi: 10.1053/jars.2003.50128. 